\title{
The effects of three days of sub-maximal-intensity mountain biking on sleep
}

\author{
Stephanie P Murphy (BSc Honours, Physiology) \\ Andrea Fuller (PhD) \\ Alison J Bentley (PhD) \\ Ingrid Avidon (PhD) \\ School of Physiology, University of the Witwatersrand Medical School, Faculty of Health Science, Johannesburg
}

\begin{abstract}
Objectives. We determined the effect of three consecutive days of sub-maximal-intensity mountain biking ( 4.5 hours per day, $\sim 64$ $\mathrm{km}$ per day), on the sleep of ten healthy, trained male and female mountain bikers.

Methods. The sleep of the mountain bikers was assessed both subjectively (visual analogue scales and sleep questionnaires) and objectively (activity data logger) on each night of mountain biking and for seven nights when they were not cycling (pre-exercise, mean of seven nights). The cyclists' mood and muscular pain were assessed each night using visual analogue scales. The cyclists slept at home in their normal environment.

Results. There was no significant difference between the mountain bikers' muscular pain and mood (calm/anxious visual analogue scale) measured during the pre-exercise stage and their pain and mood measured on each of the mountain biking nights $(p>0.05)$. However, compared with the pre-exercise stage, the mountain bikers reported that they were significantly more tired (tired/energetic visual analogue scale) on each night of cycling $(p<0.01)$. The sleep of the mountain bikers was disrupted on the night of the third day of mountain biking only. On this night, compared with the pre-exercise stage, the mountain bikers reported that they woke up more during the night (double the number of times) $(p<0.001)$, and an activity data logger recorded that they were awake for about half an hour longer during the night $(p<0.05)$

Conclusion. We have shown that three days of repeated, endurance sub-maximal mountain biking disrupted the sleep of the mountain bikers on the third night of cycling.
\end{abstract}

\section{CORRESPONDENCE:}

\section{Ingrid Avidon}

School of Physiology

University of the Witwatersrand Medical School

7 York Road

Parktown, 2193

South Africa

Tel: +27 11 717-2363

Fax: +27 11 643-2765

E-mail: Ingrid.Avidon@wits.ac.za

\section{Introduction}

Sleep functions to conserve energy, restore body tissue and downregulate body temperature. In comparison, exercise depletes energy stores, causes tissue breakdown and increases body temperature. ${ }^{1,2}$ Therefore, one might assume that exercise would promote and improve sleep quality, ${ }^{2}$ and could even be used as a non-pharmacological way of improving sleep. ${ }^{1}$ However, exercise variables such as type, intensity, duration and timing, as well as individual variables such as age, gender, body mass and fitness, all influence the relationship between exercise and sleep. ${ }^{1}$ The intensity and duration of exercise seem to be the most influential factors affecting sleep. ${ }^{2}$ Exercise of moderate intensity has been shown to improve self-reported or subjective measures of sleep. ${ }^{3}$ In comparison, high-intensity, strenuous exercise may result in disrupted sleep. ${ }^{4}$ Driver et al. ${ }^{5}$ proposed that each individual has a threshold of duration and intensity of exercise. Once this threshold is exceeded, sleep is negatively affected by the exercise.

Possibly the most physically taxing exercise events are multiday stage races of either cross-country skiing, running, road cycling, mountain biking or adventure racing. In these long-duration events, participants are required to exercise for several hours per day, and often for three or more consecutive days. In these types of exercise events you might expect a detrimental impact on sleep as a result of the long duration and often the high intensity of the exercise. In addition, competitors partaking in such events often sleep in different environments each night, and so the unfamiliar and possibly uncomfortable sleeping environments also may disturb their sleep.

To our knowledge, the effects of repeated endurance exercise on sleep have not yet been studied. Studies have been done on competitors in very long-duration events, such as ultra-triathlons, but these events take place on only one day. ${ }^{5}$ Since stage racing is becoming more popular as a competitive event, it is important to investigate the effects that the repeated endurance exercise may have on sleep, as adequate sleep is crucial for recovery, physical well-being and exercise performance. ${ }^{1}$

Therefore, the aim of our study was to determine the effect of repeated sub-maximal-intensity mountain biking, over three consecutive days, on the sleep of trained mountain bikers. We chose to assess the mountain bikers' sleep both objectively, using activity data loggers (actigraphy) as a measure of movement during the night, and subjectively, using questionnaires and visual analogue scales. To isolate the effect of the exercise on sleep and eliminate the effect of the sleeping environment, the study participants slept at home in their normal environment. 


\section{Methods}

\section{Ethical clearance}

Ethical clearance was obtained from the University of the Witwatersrand's Committee for Research on Human Subjects, which adheres to the principles of the Declaration of Helsinki (M080447); all the subjects gave written informed consent for participation.

\section{Subject recruitment}

Mountain bikers from mountain biking clubs in and around Johannesburg and Pretoria, South Africa, were asked to volunteer for the study. Comprehensive questionnaires were used to determine whether the subjects were healthy and sufficiently trained to participate safely in the study. Volunteers had to have been cycling for at least three years and training (cycling) at least six hours per week to be eligible for the study. Volunteers were excluded from the study if they were not healthy, or if they were not sufficiently trained to complete three consecutive days of mountain biking lasting four hours per day. Thereafter, the volunteers were screened for sleep disorders using the Pittsburgh Sleep Quality Index (PSQI) and screened for depression using a general health questionnaire. Volunteers who scored more than 5 on the PSQI, an indication of disturbed sleep, ${ }^{6}$ and volunteers who were depressed, were excluded from the study. Furthermore, volunteers were excluded from the study if they did not have a normal sleep routine or if they had a lifestyle or occupation that did not allow for a normal sleep routine. After screening, ten mountain bikers met all the inclusion criteria and participated in the study.

\section{Subject characteristics}

Eight males and two females $(N=10)$ between the ages of 20 and 52 years, with an average age of $37 \pm 9$ years, participated in the study. The mountain bikers had a mean \pm SD height of $1.75 \pm 0.04 \mathrm{~m}$, a mean weight of $76.8 \pm 8.9 \mathrm{~kg}$ and a mean body mass index (BMI) of $22.9 \pm 2.0 \mathrm{~kg} \cdot \mathrm{m}^{-2}$. All subjects were competent, trained riders who had been participating in mountain biking for at least three years and who were cycling at least six hours per week (range: 6 - 10 hours per week). Within the last year, five of the riders had participated in three competitive stage races lasting more than three days; three of the riders had participated in two competitive stage races lasting more than three days; and two had participated in one competitive stage race lasting more than five days.

\section{Experimental design}

The study was done in two stages - a pre-exercise stage and a mountain biking stage. During both stages, objective and subjective measures of sleep were recorded using actigraphy (activity data logger) and questionnaires, respectively. On each night of the two stages the mountain bikers were asked to wear the activity data logger on their right arm (see 'Objective measure of sleep' below). The activity data logger detects movement during sleep and is an objective measure of disrupted sleep. In addition, the mountain bikers were asked to complete questionnaires before going to bed and then again in the morning (see 'Subjective measures of sleep, pain and mood' below).

The pre-exercise stage consisted of seven days and nights with no change to the normal exercise or sleep patterns of the riders. This stage was used to establish each subject's normal sleep, pain and mood patterns.

The mountain biking stage consisted of three consecutive days in which the riders performed 4.5 hours of mountain biking each day at the Groenkloof Nature Reserve, Pretoria (1308 m above sea level), on a marked mountain biking trail within the reserve. The terrain of the trail was hilly and rocky and the cycling was performed in late August until early September (spring). The riders were asked to consume their 'normal training day' breakfast on the mornings of mountain biking, and follow a high-carbohydrate diet for the three days of cycling. Before the start of the ride, each rider's maximum heart rate was estimated at 220 minus their age. ${ }^{7}$ Each rider wore a heart rate monitor (Polar Heart rate monitor S610, Polar Electro Oy, Kempele, Finland) for the duration of the ride and was asked to maintain a heart rate of between $70 \%$ and $80 \%$ of their estimated maximum. Exercise intensity has been shown to affect sleep, and therefore the riders were asked to cycle at a set intensity in order to standardise the exercise intensity between the riders over the three days. The mountain bikers started riding by $08 \mathrm{~h} 30$ every morning, and rode continuously for 4.5 hours. They were allowed to drink water and their chosen energy drink ad lib during the cycling. In addition, each cyclist was given three PVM energy bars (PVM Nutritional Sciences, Pretoria, South Africa; carbohydrate $27 \mathrm{~g} / \mathrm{bar}$; protein $5.3 \mathrm{~g} / \mathrm{bar}$; fat $5.5 \mathrm{~g} / \mathrm{bar}$ ) and instructed to eat one bar every 90 minutes. At the end of riding, the distance and time for each rider were recorded from their bicycle computer. At the end of each day, each rider was asked to use the 10-point Borg scale to rate their perceived exertion (RPE) for the ride. The riders returned home after each day of mountain biking and slept in their normal sleeping environment. The riders were encouraged to begin fluid and carbohydrate replenishment as soon as possible after riding and eat a high-carbohydrate diet during the day. All objective and subjective data related to sleep, mood and pain were analysed on the nights after the exercise days.

On each day of the mountain biking, the microclimate was measured at 30-minute intervals throughout the cycling time. The wet and dry bulb temperatures, black globe temperature and wind speed were recorded to determine whether all the mountain bikers had exercised under similar environmental conditions.

During the study, the mountain bikers were asked to refrain from long-duration or intense exercise other than the three days of mountain biking, and to follow their normal daily activities and sleeping patterns. They were not allowed to drink alcohol and caffeinated beverages. They were asked not to use any pain medication or modalities such as massage or icing to decrease muscular pain. Furthermore, they were not allowed to take naps during the day or take sleeping pills or medications/agents that could disrupt their normal sleep patterns. They were asked to follow their normal sleep patterns and refrain from activities that could disrupt sleep (e.g. working or socialising late into the night).

\section{Objective measure of sleep}

On each night of the study, each subject wore an activity data logger (SensorMedics, Bodymedia ${ }^{\circledR}$ Body Monitoring System - SenseWear ${ }^{\circledR}$ $\mathrm{PRO}_{2}$ Armband, Milan, Italy) on their upper right arm during sleep. The armband, an activity monitor with a 2-axis accelerometer, is able to detect movement in two planes, and has been validated as a sleep detection device. ${ }^{8}$ The armband weighs approximately $200 \mathrm{~g}$, is comfortable to wear and is not disruptive to sleep. The mountain bikers put the armbands on when they switched off the light with the intention of going to sleep and removed the armband when they woke up in the morning. The armband recorded and saved the data until it was downloaded at a later stage. Based on the amount of movement detected by the armband during the night, the software calculated the total sleep time ((TST), minutes) of each subject and the amount of time he or she was awake during the night (wakefulness after sleep onset (WASO), minutes). 


\section{Subjective measures of sleep, pain and mood}

The subjects completed an evening form before going to bed to subjectively assess their muscular pain and mood. They were asked to indicate their current muscular pain on a $100 \mathrm{~mm}$ visual analogue scale (VAS) anchored at 'no pain', and 'worst pain ever felt'. They were also asked to indicate their current mood on two separate $100 \mathrm{~mm}$ VASs - one anchored at 'calm' and 'anxious' and the other at 'tired' and 'energetic'. 9

On each morning of the study, the subjects completed the Wits Dial-A-Bed morning form within 20 minutes of waking up. They recorded the time they went to bed (lights off), the time they thought it had taken to fall asleep (sleep-onset latency (SOL), minutes), the number of times they thought they had woken up during the night (number of awakenings), how long they thought they were awake during the night (WASO, minutes), and the time they woke up in the morning. From this information we were able to calculate their time in bed ((TIB), minutes) as the time from lights off to the time that they woke up in the morning, TST (minutes) as TIB minus (SOL + WASO), sleep efficiency ((SE), percentage) as TST/TIB x 100. Furthermore, the mountain bikers were asked to rate their sleep quality (SQ) on a $100 \mathrm{~mm}$ VAS line anchored at 'worst sleep ever' and 'best sleep ever'.

\section{Data analysis}

To establish the normal sleep variables, mood and pain for each subject, a mean of each of the variables was calculated from the preexercise stage. The VAS data (pain, mood and sleep quality) were normalised with an arcsine transformation before parametric statistical analysis. A repeated-measures analysis of variance (RM ANOVA) was used to determine whether there was a difference between muscular pain, mood and objective and subjective sleep variables measured in the pre-exercise phase (mean of pre-exercise nights) and on each night after the three mountain biking days. A Dunnett's multiple comparisons test was used as a post test to compare the mountain bikers' pre-exercise pain, mood and sleep variables with the variables measured on each night of the three mountain biking days.

The subject's riding distance and riding speed on each day of mountain biking were compared using a RM ANOVA, with a Tukey post test. The RPE on each day of mountain biking was compared using the Friedman test with a Dunn post test.

The data, except for the RPE (median, upper $95 \% \mathrm{Cl}$, lower $95 \%$ $\mathrm{Cl}$ ), are expressed as mean $\pm \mathrm{SD}$. For all statistical analysis $p<0.05$ was considered significantly different.

\section{Results \\ Mountain biking data}

On each day of mountain biking there was no difference in the riders reported RPE $(p=0.75)$, riding distance $(p=0.18, \mathrm{~F}=1.92)$ and average riding speed $(p=0.07, \mathrm{~F}=3.21)$. The median (upper and lower $95 \% \mathrm{Cl}$ ) RPE for the mountain bikers during the exercise stage was 5 $(5 ; 6)$, the mean $\pm S D$ riding distance was $63.7 \pm 3.8 \mathrm{~km}$ and the mean $\pm \mathrm{SD}$ riding speed was $14.4 \pm 0.6 \mathrm{~km} \cdot \mathrm{h}^{-1}$.

The mountain bikers rode under similar weather conditions. On all the riding days, the dry bulb temperature ranged from $6.5^{\circ} \mathrm{C}$ in the morning $(07 \mathrm{~h} 00)$ to $26^{\circ} \mathrm{C}$ by $13 \mathrm{~h} 00$. Wet bulb temperature ranged from $6^{\circ} \mathrm{C}$ in the morning to $19^{\circ} \mathrm{C}$ at $13 \mathrm{~h} 00$. Black globe temperature ranged from $14.5^{\circ} \mathrm{C}$ in the morning to $44.2^{\circ} \mathrm{C}$ at $13 \mathrm{~h} 00$. Wind speed ranged from 0 to $5.3 \mathrm{~m} \cdot \mathrm{s}^{-1}$.
Objective and subjective measures of sleep (pre-exercise versus mountain biking nights)

The mountain bikers' objective and subjective measures of sleep are given in Table I. There were no significant differences between the pre-exercise and mountain biking nights for the riders' subjective TIB $(p=0.54, \mathrm{~F}=0.66)$, TST $(p=0.35, \mathrm{~F}=1.16)$, objective TST $(p=0.52$, $\mathrm{F}=0.65)$, subjective $\mathrm{SOL}(p=0.54, \mathrm{~F}=0.73)$, subjective WASO $(p=0.56$, $\mathrm{F}=0.69)$, subjective $\mathrm{SQ}(p=0.56, \mathrm{~F}=0.71)$ and subjective $\mathrm{SE}(p=0.24$, $F=1.51$ ).

There was a significant difference between the subjective number of awakenings reported by the mountain bikers during the pre-exercise and mountain biking nights $(p=0.02, \mathrm{~F}=4.32$, Table I). Compared with the pre-exercise stage, the mountain bikers reported that they woke up more on the night after the third day of mountain biking $(p<0.001$, Table I), but not on the night after the first or second day of mountain biking ( $p>0.05$, Table I).

There was a significant difference between objective WASO recorded by the armbands on the pre-exercise and the mountain biking nights $(p=0.05, \mathrm{~F}=2.92$, Table I). Compared with the preexercise stage, objective WASO was significantly increased on the night of the third day of mountain biking by more than 30 minutes $(p \leq 0.05)$, but not on the night after the first $(p>0.05)$ or second day $(p>0.05)$ of mountain biking.

Table II shows the number of subjects, out of ten, compared with baseline, who showed an increase, a decrease or no change in their sleep measures on each of the three nights.

\section{Muscular pain and mood (pre-exercise versus mountain biking nights)}

The muscular pain and mood data for the mountain bikers are given in Table I. There was no significant difference between the intensity of muscular pain experienced by the mountain bikers in the pre-exercise stage and after each of the mountain biking days $(p=0.07$, $\mathrm{F}=2.59$, Table I).

There was no significant difference between the mountain bikers' mood on the calm/anxious scale in the pre-exercise stage compared with the mountain biking nights $(p=0.23, \mathrm{~F}=1.15$, Table I). However, there was a significant difference between the subjects' mood on the tired/energetic scale when measured in the pre-exercise stage compared with the mountain biking nights $(p=0.0016, \quad \mathrm{~F}=6.48)$. Compared with the pre-exercise stage, the subjects reported that they were significantly more tired at night on all three days of mountain biking $(p<0.01$, Table I)

\section{Discussion}

We assessed the sleep of mountain bikers, both objectively and subjectively, on two separate occasions: when they were not exercising (pre-exercise phase) and on each night of three consecutive days of mountain biking. Our results show that three days of sub-maximalintensity mountain biking, for four and a half hours per day, disrupts sleep on the third night only. Compared with the pre-exercise phase, on the night of the third day of mountain biking the riders reported that they woke up more often during the night and spent more than 30 minutes extra awake when measured by an activity data logger, worn during sleep as an objective measure of sleep (Table I).

We recruited ten mountain bikers with no sleep abnormalities who successfully fulfilled all the criteria for participation in the study and who were prepared to participate in the lengthy study protocol. However, our relatively small sample size may have resulted in the absence of significant change in some of the other objective 
TABLE I. Mountain bikers' objective and subjective measures of sleep, pain and mood for the pre-exercise phase and on each night of three consecutive days of mountain biking

\begin{tabular}{|c|c|c|c|c|c|}
\hline & & Pre-exercise & Night 1 & Night 2 & Night 3 \\
\hline \multirow[t]{2}{*}{$\begin{array}{l}\text { Objective measure } \\
\text { of sleep }\end{array}$} & Total sleep time (TST, min.) & $\begin{array}{l}400.2 \pm 30.6 \\
{[380.1-450.4]}\end{array}$ & $\begin{array}{l}350.8 \pm 28.3 \\
{[339.1-400.3]}\end{array}$ & $\begin{array}{l}371.1 \pm 20.5 \\
{[340.2-412.4]}\end{array}$ & $\begin{array}{l}330.2 \pm 25.5 \\
{[310.5-385.3]}\end{array}$ \\
\hline & $\begin{array}{l}\text { Wakefulness after sleep } \\
\text { onset (WASO, min.) }\end{array}$ & $\begin{array}{l}39.7 \pm 25.6 \\
{[10.2-78.5]}\end{array}$ & $\begin{array}{l}68.7 \pm 42.2 \\
{[11.5-143.1]}\end{array}$ & $\begin{array}{l}43.8 \pm 25.2 \\
{[5.6-73.9]}\end{array}$ & $\begin{array}{l}75.7 \pm 57.7^{*} \\
{[6.5-189.2]}\end{array}$ \\
\hline \multirow[t]{7}{*}{$\begin{array}{l}\text { Subjective measure } \\
\text { of sleep }\end{array}$} & $\begin{array}{l}\text { Time in bed } \\
\text { (TIB, min.) }\end{array}$ & $\begin{array}{l}422.4 \pm 20.3 \\
{[390.3-480.6]}\end{array}$ & $\begin{array}{l}420.1 \pm 15.6 \\
{[385.6-453.2]}\end{array}$ & $\begin{array}{l}421.6 \pm 16.5 \\
{[390.7-460.7]}\end{array}$ & $\begin{array}{l}419.7 \pm 19.1 \\
{[385.6-460.7]}\end{array}$ \\
\hline & $\begin{array}{l}\text { Total sleep time } \\
\text { (TST, min.) }\end{array}$ & $\begin{array}{l}395.2 \pm 28.2 \\
{[360.0-450.3]}\end{array}$ & $\begin{array}{l}380.6 \pm 22.2 \\
{[350.6-448.6]}\end{array}$ & $\begin{array}{l}380.0 \pm 33.4 \\
{[344.7-440.3]}\end{array}$ & $\begin{array}{l}374.6 \pm 18.4 \\
{[330.8-428.2]}\end{array}$ \\
\hline & $\begin{array}{l}\text { Sleep-onset latency } \\
\text { (SOL, min.) }\end{array}$ & $\begin{array}{l}15.7 \pm 6.4 \\
{[3.8-25.0]}\end{array}$ & $\begin{array}{l}26.0 \pm 22.2 \\
{[5.0-90.0]}\end{array}$ & $\begin{array}{l}32.0 \pm 23.1 \\
{[5.0-100.0]}\end{array}$ & $\begin{array}{l}25.0 \pm 14.8 \\
{[5.0-55.2]}\end{array}$ \\
\hline & Number of awakenings & $\begin{array}{l}1.5 \pm 1.0 \\
{[0.0-2.8]}\end{array}$ & $\begin{array}{l}2.2 \pm 1.6 \\
{[0.0-5.0]}\end{array}$ & $\begin{array}{l}2.1 \pm 1.3 \\
{[0.0-5.0]}\end{array}$ & $\begin{array}{l}3.0 \pm 2.0^{\ddagger} \\
{[0.0-6.0]}\end{array}$ \\
\hline & $\begin{array}{l}\text { Wakefulness after sleep } \\
\text { onset (WASO, min.) }\end{array}$ & $\begin{array}{l}11.3 \pm 11.5 \\
{[3.8-38.8]}\end{array}$ & $\begin{array}{l}14.3 \pm 18.2 \\
{[4.2-60.0]}\end{array}$ & $\begin{array}{l}9.6 \pm 13.7 \\
{[2.0-73.9]}\end{array}$ & $\begin{array}{l}20.7 \pm 28.2 \\
{[1.8-90.0]}\end{array}$ \\
\hline & $\begin{array}{l}\text { Sleep efficiency (SE) } \\
(\%)\end{array}$ & $\begin{array}{l}93.6 \pm 6.4 \\
{[90.1-97.6]}\end{array}$ & $\begin{array}{l}90.5 \pm 6.9 \\
{[88.3-96.4]}\end{array}$ & $\begin{array}{l}90.0 \pm 6.7 \\
{[88.4-95.3]}\end{array}$ & $\begin{array}{l}89.0 \pm 9.2 \\
{[83.2-93.1]}\end{array}$ \\
\hline & $\begin{array}{l}\text { Sleep quality (SQ) } \\
(0-100 \mathrm{~mm}, \mathrm{VAS})\end{array}$ & $\begin{array}{l}56.8 \pm 9.5 \\
{[41.5-70.8]}\end{array}$ & $\begin{array}{l}58.7 \pm 15.8 \\
{[29.0-74.2]}\end{array}$ & $\begin{array}{l}62.2 \pm 12.9 \\
{[46.3-78.4]}\end{array}$ & $\begin{array}{l}53.0 \pm 12.9 \\
{[39.1-69.4]}\end{array}$ \\
\hline $\begin{array}{l}\text { Subjective measure } \\
\text { of muscular pain }\end{array}$ & $\begin{array}{l}\text { Intensity of pain } \\
(0-100 \mathrm{~mm}, \text { VAS })\end{array}$ & $3.9 \pm 4.9$ & $15.6 \pm 21.9$ & $13.8 \pm 12.6$ & $7.1 \pm 8.6$ \\
\hline \multirow[t]{2}{*}{$\begin{array}{l}\text { Subjective measure } \\
\text { of mood }\end{array}$} & $\begin{array}{l}\text { Calm-anxious scale } \\
\text { (0 - } 100 \text { mm, VAS) }\end{array}$ & $24.5 \pm 13.3$ & $34.1 \pm 19.2$ & $36.4 \pm 15.7$ & $35.0 \pm 13.2$ \\
\hline & $\begin{array}{l}\text { Tired-energetic scale } \\
(0-100 \mathrm{~mm}, \mathrm{VAS})\end{array}$ & $47.9 \pm 16.3$ & $25.2 \pm 16.9^{\dagger}$ & $21.9 \pm 15.3^{\dagger}$ & $23.6 \pm 16.4^{\dagger}$ \\
\hline \multicolumn{6}{|c|}{ Data presented as mean $\pm S D, N=10$. Data in [ ] - range. } \\
\hline \multicolumn{6}{|l|}{${ }^{*} p<0.05$ versus pre-exercise. } \\
\hline \multicolumn{6}{|l|}{$\dagger_{p<0.01 \text { versus pre-exercise. }}$} \\
\hline${ }_{p<0.001 \text { versus pre-exe }}$ & & & & & \\
\hline
\end{tabular}

and subjective sleep variables. The mountain bikers all rode the same mountain bike route at a similar RPE, for a similar time, at a similar time of day (and environmental conditions), at a similar speed, and with adequate energy provision. Furthermore, all the subjects slept at home in their own beds each night, allowing us to remove extraneous factors such as environmental conditions, exercise intensity, exercise duration, inadequate nutrition and unaccustomed sleeping environment, which could affect sleep, from our investigation. The subjects were asked to record the time they went to bed and the time they woke up each morning. From this data we were able to calculate their TIB. There was no significant difference in the TIB data between the pre-exercise and cycling nights (Table I), confirming that the subjects did keep to a regular schedule across the study. The mountain bikers were asked to ride each day at a similar sub-maximal heart rate and RPE, and not alter their intensity of riding which would occur if they were racing or allowed to set their own riding intensity. These findings mean that our data cannot be extrapolated to a real racing situation. Similarly, the riders all rode under similar mild environmental conditions in the months of August to early September (spring). Exercise performed in hot environmental conditions, unlike our riding conditions, can increase core body temperature. ${ }^{10}$ An increased core body temperature can influence measures of sleep, ${ }^{11}$ but has also been shown to have no effect on sleep. ${ }^{6,12}$ Therefore, in our study, we can only report on the effects of the riding on measures of sleep in mild environmental conditions and cannot extrapolate our data to warmer environmental conditions that may occur during summer months.

We assessed the sleep in the mountain bikers both objectively and subjectively. The gold standard for objective sleep recording is polysomnography (PSG). While PSG may be a better method of recording sleep objectively, it would have added an additional unwanted component to the study, i.e. that of sleeping in a strange environment. Therefore, for our objective assessment of sleep, we used an activity data logger to assess movement during sleep as a marker of disturbed or restless sleep. Actigraphy is becoming a popular method of assessing total sleep time and movement during sleep, a measure of WASO. ${ }^{8,13,14}$ We also included a subjective sleep assessment in our study, as this form of assessment provides valuable information regarding an individual's perception of their sleep. ${ }^{15,16}$ Furthermore, subjective sleep estimates tend to differ from objective measurements of sleep, ${ }^{15,17,18}$ and therefore it is important for studies to include both assessments when investigating sleep.

We hypothesised that the sleep of the cyclists would be disrupted as a result of the repeated mountain biking, becoming increasingly disrupted with each day of riding. We found that the sleep of the mountain bikers was disrupted only on the third night of exercise. On this night, compared with the pre-exercise nights, the cyclists reported that they woke up more often during the night (double the number of times) and their activity data loggers showed that they were awake for 34 minutes longer during the night (increased 
TABLE II. Number of subjects (out of total of 10 subjects) who showed an increase $(\uparrow$ ), decrease $(\downarrow)$ or no change $(\leftrightarrow)$ in their measures of sleep, compared with baseline, on each night after cycling (data are shown as the number of subjects/total number of 10 subjects)

\begin{tabular}{|c|c|c|c|c|}
\hline & & Night 1 & Night 2 & Night 3 \\
\hline $\begin{array}{l}\text { Objective measure of } \\
\text { sleep }\end{array}$ & $\begin{array}{l}\text { Wakefulness after sleep onset } \\
\text { (WASO, min.) }\end{array}$ & $\begin{array}{l}7 / 10 \uparrow \\
2 / 10 \downarrow \\
1 / 10 \leftrightarrow\end{array}$ & $\begin{array}{l}5 / 10 \uparrow \\
4 / 10 \downarrow \\
1 / 10 \leftrightarrow\end{array}$ & $\begin{array}{l}8 / 10 \uparrow \\
1 / 10 \downarrow \\
1 / 10 \leftrightarrow\end{array}$ \\
\hline \multirow[t]{5}{*}{$\begin{array}{l}\text { Subjective measure of } \\
\text { sleep }\end{array}$} & $\begin{array}{l}\text { Sleep-onset latency } \\
\text { (SOL, min.) }\end{array}$ & $\begin{array}{l}5 / 10 \uparrow \\
5 / 10 \downarrow\end{array}$ & $\begin{array}{l}5 / 10 \uparrow \\
5 / 10 \downarrow\end{array}$ & $\begin{array}{l}5 / 10 \uparrow \\
5 / 10 \downarrow\end{array}$ \\
\hline & Number of awakenings & $\begin{array}{l}4 / 10 \uparrow \\
2 / 10 \downarrow \\
4 / 10 \leftrightarrow\end{array}$ & $\begin{array}{l}4 / 10 \uparrow \\
1 / 10 \downarrow \\
5 / 10 \leftrightarrow\end{array}$ & $\begin{array}{l}7 / 10 \uparrow \\
1 / 10 \downarrow \\
2 / 10 \leftrightarrow\end{array}$ \\
\hline & $\begin{array}{l}\text { Wakefulness after sleep onset } \\
\text { (WASO, min.) }\end{array}$ & $\begin{array}{l}4 / 10 \uparrow \\
3 / 10 \downarrow \\
3 / 10 \leftrightarrow\end{array}$ & $\begin{array}{l}4 / 10 \uparrow \\
4 / 10 \downarrow \\
2 / 10 \leftrightarrow\end{array}$ & $\begin{array}{l}6 / 10 \uparrow \\
2 / 10 \downarrow \\
2 / 10 \leftrightarrow\end{array}$ \\
\hline & $\begin{array}{l}\text { Sleep efficiency (SE) } \\
(\%)\end{array}$ & $\begin{array}{l}3 / 10 \uparrow \\
4 / 10 \downarrow \\
3 / 10 \leftrightarrow\end{array}$ & $\begin{array}{l}2 / 10 \uparrow \\
3 / 10 \downarrow \\
5 / 10 \leftrightarrow\end{array}$ & $\begin{array}{l}1 / 10 \uparrow \\
6 / 10 \downarrow \\
3 / 10 \leftrightarrow\end{array}$ \\
\hline & $\begin{array}{l}\text { Sleep quality (SQ) } \\
(0-100 \mathrm{~mm}, \mathrm{VAS})\end{array}$ & $\begin{array}{l}5 / 10 \uparrow \\
3 / 10 \downarrow \\
2 / 10 \leftrightarrow\end{array}$ & $\begin{array}{l}5 / 10 \uparrow \\
4 / 10 \downarrow \\
1 / 10 \leftrightarrow\end{array}$ & $\begin{array}{l}1 / 10 \uparrow \\
6 / 10 \downarrow 3 / 10 \leftrightarrow \\
3 / 10 \leftrightarrow\end{array}$ \\
\hline
\end{tabular}

WASO). As seen in Table II, on the third night of cycling, more of the riders recorded an increase in their time WASO (objective), more of the riders experienced an increase in their number of awakenings during the night and an increase in their subjective WASO, and the $\mathrm{SE}$ and $\mathrm{SQ}$ decreased in more of the riders. Even though their sleep was unaffected on the first and second nights of mountain biking, the mountain bikers felt more tired, compared with the pre-exercise stage, as assessed by the VAS, on each of the three mountain biking nights. The changes in the mountain bikers' sleep on the third night of exercise were not as a result of muscular pain, nor a change in the level of anxiety, since there was no difference in the riders pain or mood between the pre-exercise stage and the three nights of mountain biking. In our study, the exclusion of pain and anxiety as extraneous factors influencing sleep was an important finding since concomitant depression, pain and anxiety can have a negative impact on $\mathrm{SQ}^{19,20}$ and would have confounded the findings.

Our study is the first to assess the effect of repeated endurance exercise on subjective and objective measures of sleep. Previous studies have investigated the effect of one day of endurance exercise on objective measures of sleep. Trained marathon runners experienced no difference in their sleep after they rested, ran a $15 \mathrm{~km}$ race or a $42.2 \mathrm{~km}$ race. ${ }^{5}$ However, after the same subjects participated in an ultra-triathlon, which lasted up to 12 hours, the amount of rapid eye movement (REM) sleep was reduced, REM onset was delayed and WASO was increased by up to $40 \%{ }^{5}$,

In our study, the sleep of the mountain bikers was not affected on the first or second night of the mountain biking, but may have been affected if they had ridden for longer each day or if they had ridden at a higher intensity. The mountain bikers were asked to ride at a similar sub-maximal intensity on each day of riding and they rated their perceived exertion as 5 on the 10-point Borg scale on each day. We were therefore not able to assess the effect of increased riding intensity on SQ. In our study, the repeated four and a half hours of sub-maximal-intensity mountain biking may have resulted in sleep disruption by the third night as a result of a cumulative effect of the exercise. Indeed, the proposal of a threshold of intensity and duration of exercise by Driver et al. ${ }^{5}$ seems to apply to the mountain bikers in our study; they may have reached their threshold only by the third day of exercise.
A possible factor to explain the sleep disruption after three days of riding, although not measured in our study, is that of circulating cytokines. ${ }^{4,21,22}$ During exercise cytokines, such as interleukin-1 (IL-1), interleukin-6 (IL-6) and tumour necrosis factor- $\alpha$ (TNF- $\alpha$ ), which also play a role in regulating sleep, increase. ${ }^{4} \mathrm{IL}-1$ and TNF- $\alpha$ regulate sleep by controlling body temperature ${ }^{4}$ and higher concentrations of IL- 6 and TNF- $\alpha$ have been found in people who have sleep disorders associated with increased wakefulness. ${ }^{4}$ In our study, high concentrations of IL-6 may explain the increased wakefulness observed in the mountain bikers on the night of the third day of exercise.

Further research would be needed to investigate the effects of repeated mountain biking over more than three days as well as a higher intensity of exercise. Top international competitive events require mountain bikers to ride for seven or more days, sometimes for more than six hours per day. It would be interesting to determine the effect of this mountain biking on a cyclist's sleep over each day and to measure their pain, mood, body temperature, cytokine profile and cycling performance over the days. In addition, the role of sleeping in an unfamiliar environment after cycling should also be considered to obtain a more complete picture of the endurance cycling event. In our study we have shown that three days of repeated endurance sub-maximal exercise do have a negative effect on the sleep of the mountain bikers, but more research needs to be carried out to determine the exact mechanisms of these effects and also to determine the impact that these changes in sleep may have on the safety and performance of the mountain bikers.

\section{Acknowledgements}

We would like to thank the WITS Dial-A-Bed Sleep Laboratory and the University of the Witwatersrand's Brain Function Research Group for funding.

\section{RefERENCES}

1. Driver HS, Taylor SR. Exercise and sleep. Sleep Med Rev 2000;4:387402.

2. Youngstedt SD. Effects of exercise on sleep. Clin Sports Med 2005;24:355365 
3. Singh NA, Clements KM, Fiatarone MA. A randomized controlled trial of the effect of exercise on sleep. Sleep 1997;20:95-101.

4. Santos RV, Tufik S, De Mello MT. Exercise, sleep and cytokines: Is there a relation? Sleep Med Rev 2007;11:231-239.

5. Driver HS, Rogers GG, Mitchell D, et al. Prolonged endurance exercise and sleep disruption. Med Sci Sports Exerc 1994;26:903-907.

6. Youngstedt SD, Kripke DF, Elliott JA. Is sleep disturbed by vigorous latenight exercise? Med Sci Sports Exerc 1991;31:864-869.

7. Whaley MH, Brubaker PH, Otto RM. ACSM's Guidelines for Exercise Testing and Prescription. 7th ed. Philadelphia: Lippincott Williams and Wilkins, 2005:349.

8. Miwa H, Sasahara S, Matsui T. Roll-over detection and sleep quality measurement using a wearable sensor. Conf Proc IEEE Eng Med Biol Soc 2007:1507-1510.

9. Polman R, Nicholls AR, Cohen J, et al. The influence of game location and outcome on behaviour and mood states among professional rugby league players. J Sports Sci 2007;25:1491-1500.

10. Gonzales-Alonso J, Teller C, Andersen SL, et al. Influence of body temperature on the development of fatigue during prolonged exercise in the heat. J Appl Physiol 1999;86:1032-1039.

11. Youngstedt SD. Effects of exercise on sleep. Clin Sports Med 2005;24:355365.

12. O'Connor PJ, Breus MJ, Youngstedt SD. Exercise-induced increase in core body temperature does not disrupt behavioural measures of sleep. Physiol Behav 1998;64:213-217.
13. Landis CA, Frey CA, Lentz MJ, et al. Self-reported sleep quality and fatigue correlates with actigraphy in midlife women with fibromyalgia. Nurs Res 2003;52:140-147.

14. Bruni O, Russo PM, Violani C, et al. Sleep and migraine: an actigraphy study. Cephalgia 2004;24:134-139.

15. Perlis ML, Giles DE. Psychophysiological insomnia: the behavioural model and a neurocognitive perspective. J Sleep Res 1997;6:179-188.

16. Baker FC, Driver HS. Self-reported sleep across the menstrual cycle in young, healthy women. J Psychosom Res 2004;56:239-243.

17. Chervin RD, Guilleminault C. Overestimation of sleep latency by patients with suspected hypersomnolence. Sleep 1996;19:94-100.

18. Baker FC, Maloney S, Driver HS. A comparison of subjective estimates of sleep with objective polysomnographic data in healthy men and women. J Psychosom Res 1999;47:335-341.

19. Lavigne GJ, McMillan D, Zucconi M. Pain and sleep In: Kryger MH, Roth T, Dement WC, eds. Principles and Practice of Sleep Medicine. 3rd ed. Philadelphia: Elsevier Saunders, 2005:1246-1255.

20. Ohayon MM. Chronic pain and sleep. Int J Sleep Disorders 2006;1:16-

21. Haahr PM, Pedersen BK, Fomsgaard A, et al. Effect of physical exercise on in vitro production of interleukin 1, interleukin 6 , tumour necrosis factor-alpha, interleukin 2 and interferon-gamma. Int J Sports Med 1991;12:223-227.

22. Moldoveanu AI, Shephard RJ, Shek PN. The cytokine response to physical activity and training. Sports Med 2001;31:115-144. 